\title{
No Menstrual Cyclicity in Mood and Interpersonal Behaviour in Nine Women with Self-Reported Premenstrual Syndrome
}

\author{
Renske C. Bosman ${ }^{\mathrm{a}}$ Casper J. Albers ${ }^{\mathrm{a}}$ Jettie de Jong ${ }^{\mathrm{a}} \quad$ Nikolaos Batalas $^{\mathrm{b}}$ \\ Marije aan het $\operatorname{Rot}^{\mathrm{a}, \mathrm{c}}$ \\ a Department of Psychology, University of Groningen, Groningen, The Netherlands; \\ ${ }^{b}$ Department of Industrial Design, Eindhoven University of Technology, Eindhoven, The Netherlands; \\ 'School for Behavioural and Cognitive Neurosciences, University of Groningen, Groningen, The Netherlands
}

\section{Keywords}

Daily ratings - Ecological momentary assessment .

Experience sampling method - Menstrual cycle ·

Premenstrual syndrome

\begin{abstract}
Background/Aims: Before diagnosing premenstrual dysphoric disorder (PMDD), 2 months of prospective assessment are required to confirm menstrual cyclicity in symptoms. For a diagnosis of premenstrual syndrome (PMS), this is not required. Women with PMDD and PMS often report that their symptoms interfere with mood and social functioning, and are said to show cyclical changes in interpersonal behaviour, but this has not been examined using a prospective approach. We sampled cyclicity in mood and interpersonal behaviour for 2 months in women with selfreported PMS. Methods: Participants met the criteria for PMS on the Premenstrual Symptoms Screening Tool (PSST), a retrospective questionnaire. For 2 menstrual cycles, after each social interaction, they used the online software TEMPEST to record on their smartphones how they felt and behaved. We examined within-person variability in negative affect, posi-
\end{abstract}

\begin{tabular}{ll}
\hline KARGER & $\begin{array}{l}\text { C } 2018 \text { The Author(s) } \\
\text { Published by S. Karger AG, Basel }\end{array}$ \\
E-Mail karger@karger.com & $\begin{array}{l}\text { This article is licensed under the Creative Commons Attri- } \\
\text { bution-NonCommercial-NoDerivatives 4.0 International } \\
\text { www.karger.com/psp }\end{array}$ \\
& $\begin{array}{l}\text { License (CC BY-NC-ND) (http://www.karger.com/Ser- } \\
\text { vices/OpenAccessLicense). Usage and distribution for }\end{array}$
\end{tabular}

tive affect, quarrelsomeness, and agreeableness. Results: Participants evaluated TEMPEST as positive. However, we found no evidence for menstrual cyclicity in mood and interpersonal behaviour in any of the individual women $(n=9)$. Conclusion: Retrospective questionnaires such as the PSST may lead to oversampling of PMS. The diagnosis of PMS, like that of PMDD, might require 2 months of prospective assessment.

(c) 2018 The Author(s) Published by S. Karger AG, Basel

\section{Introduction}

Premenstrual dysphoric disorder (PMDD) is considered a depressive disorder [1]. The diagnosis requires at least 1 marked psychological symptom (e.g., affective lability, irritability, or depressed mood) and at least 4 additional symptoms. Two months of daily symptom ratings are required to confirm that the symptoms are cyclical (i.e., present during the premenstrual phase and otherwise absent) and interfere with daily life. A PMDD diagnosis is made prospectively because previous studies have shown that this helps to differentiate PMDD from 
other depressive disorders [2,3]. Women with PMDD or premenstrual syndrome (PMS) frequently report that their symptoms interfere with social functioning [4] and are said to show cyclical changes in interpersonal behaviour, particularly quarrelsomeness [5]. While premenstrual mood symptoms might be associated with premenstrual increases in quarrelsomeness, this has not been examined prospectively in women with PMS.

Daily symptom ratings, or diaries, are less likely to overestimate symptom severity than measures considering the past month [5]. However, diaries remain subject to memory biases, as people are asked to reconstruct each day. Morning experiences may be remembered inaccurately at night [6] and symptoms may vary throughout the day [7]. The experience sampling method (ESM), also known as an ecological momentary assessment (EMA), has been shown to complement diaries $[6,8]$. Like diary data, ESM/EMA data provide insight into both withinand between-person variability in momentary states. Unlike diaries, ESM/EMA can be used to detect within-day patterns [6]. Event-contingent recording (ECR) is a type of ESM/EMA that asks people to indicate their state following prespecified events. A validated ECR method is available for assessing mood and interpersonal behaviour (e.g., negative affect [NA] and quarrelsomeness) during social interactions [9]. This method allows the prospective assessment of how people feel and behave during interactions with others.

In the present ECR study, 9 women with self-reported PMS reported on their everyday social interactions for 2 months. The online software TEMPEST [10] was used to administer the ECR questionnaires via the participants' smartphones. PMS was studied because prospective ratings are not currently a requirement for diagnosing PMS, while they are a requirement for diagnosing PMDD. We postulated that our results might show that prospective ratings may also aid in diagnosing PMS. Additionally, as past studies employing ECR of social interactions have exclusively used paper questionnaires and lasted less than 1 month, we studied participant satisfaction with TEMPEST.

\section{Method}

\section{Participants}

Advertisements posted in public buildings around the city asked women with premenstrual complaints to participate in a smartphone diary study. Respondents $(n=22)$ completed the Premenstrual Symptoms Screening Tool (PSST) [11]. Inclusion criteria were: scoring "moderate" or "severe" on at least 1 of the 4 core symptoms and on at least 4 other symptoms listed in part A of the PSST and at least "mild" on at least 1 of the items in part B, age $18-40$ years, a regular menstrual cycle ( $28 \pm 3$ days), owning a suitable smartphone, no past or present diagnosis of a psychiatric disorder, not currently using psychotropic medication, not using hormonal contraceptives for at least 3 months prior to study entry, no current pregnancy, and not breastfeeding for at least 9 months prior to study entry. Ten respondents met these criteria and provided written informed consent; 9 completed this study. The Ethics Committee of Psychology of the University of Groningen approved this study.

\section{Measures}

In addition to the PSST, the Premenstrual Assessment Form (PAF) [12] was used to assess the severity of premenstrual complaints. The Quick Inventory of Depressive Symptomatology (QIDS; range 0-27) [13] was used to measure depression severity in the past week. The System Usability Scale (SUS; range 0-100) [14] evaluated participants' experiences with TEMPEST. A formal, system-independent representation of the ECR questionnaire that was running in TEMPEST is available at https://osf.io/j7ngw/.

The ECR questionnaires asked about the context of each social interaction (e.g., gender and role of the interaction partner), included items from the Dutch language Social Behaviour Inventory [15] for assessing quarrelsomeness, agreeableness, dominance, and submissiveness, and sampled NA and positive affect (PA) using 5 and 4 adjectives, respectively [16].

A daily questionnaire was completed each morning for obtaining data on participants' menstruation (absent vs. present).

\section{Data Analysis}

The data were analysed with longitudinal Bayesian MCMC models. Daily mean levels of NA, PA, quarrelsomeness, and agreeableness were created so the data could be analysed with time series models for measurements equidistant in time. These mean levels were transformed to lie within the interval $(0,1)$ and were subsequently modelled through $\beta$-distributions (see https://osf.io/ j7ngw/ for details).

Several increasingly complex group and individual models were fitted to the data. Analyses started with model 1, which included the number of days $\left(N_{i}=1,2, \ldots, n\right)$ for person $i(i=\mathrm{A}, \ldots$, I). In model 2 the spread was dependent on the number of social interactions per day. Model 3 included a moving average, thus taking the score of the previous day into account to predict the value of the following day. Dummy variables for the menstrual phases were included in model 4 , at both a group level (all participants receiving the same estimates; model $4 \mathrm{~A}$ ) and an individual level (all participants receiving person-specific estimates; model 4B). Model selection was based on the deviance information criterion [17], a measure of model fit that penalises for complexity, with a lower value indicating a better fit. When the difference in deviance information criterion values exceeded 10 , a model was discarded for a less parsimonious one [18].

The menstrual phase, based on the days on which a participant reported menstruation, varied in duration (range: 5-8 days). The premenstrual phase was defined as the 5 days preceding the menstrual phase (i.e., late luteal phase). The postmenstrual phase was defined as the 7 days following the menstrual phase (i.e., late follicular phase). The intermenstrual phase entailed the remaining cycle days; these were typically the early luteal days. 


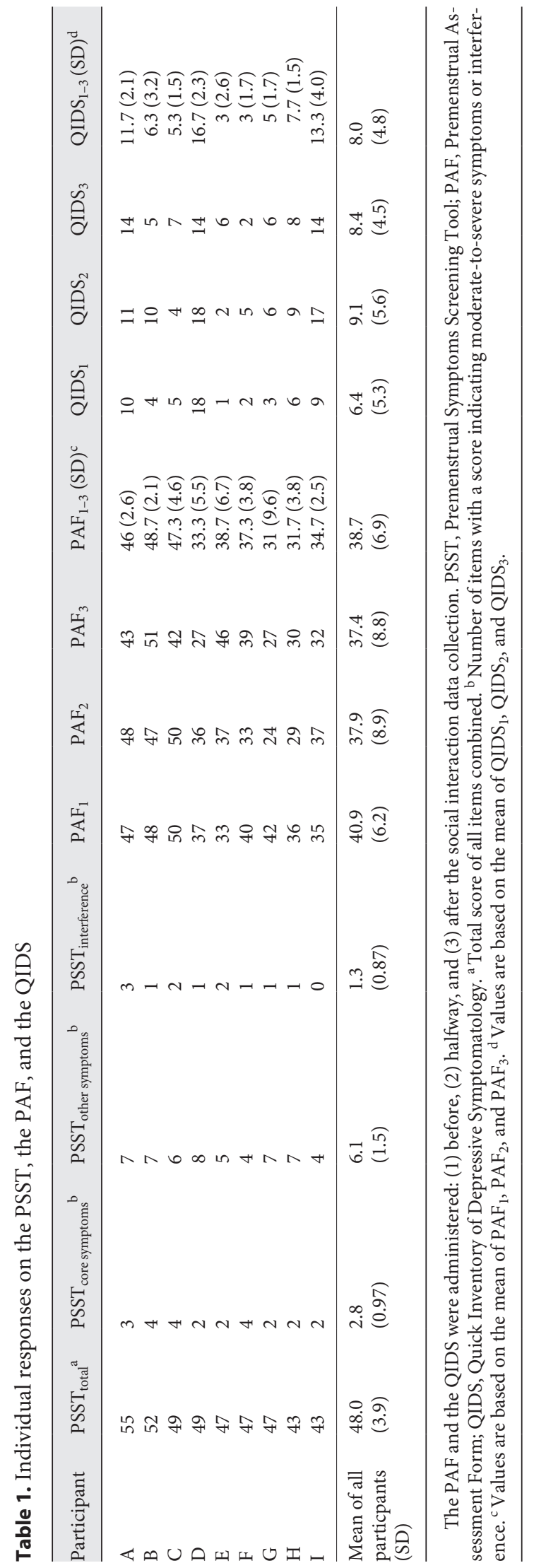

\section{Results}

\section{Retrospective Measures}

Table 1 provides individual responses on the PSST, the PAF, and the QIDS. According to the PSST, all of the participants except participant I had moderate-to-severe PMS. Participant I had the same PSST total score as participant $\mathrm{H}$, but her symptoms interfered only mildly with her daily life. Nonetheless, her average PAF score across 3 consecutive months $\left(\mathrm{PAF}_{1-3}\right)$ was higher than that of 3 other participants.

The Spearman correlation $r$ between the PSST and the $\mathrm{PAF}_{1-3}$ was $0.66(n=9, p=0.054)$, confirming that both questionnaires tap into the same construct. The correlations between the PSST and the QIDS $_{1-3}$ and between the $\mathrm{PAF}_{1-3}$ and the QIDS $_{1-3}$ were $r=0.11(p=0.74)$ and $r=$ $-0.14(p=0.72)$, respectively, indicating that, in our sample, PMS symptoms were mostly unrelated to depressive symptoms.

\section{ECR Data}

Participants recorded their interactions for 61-77 days (mean $=65.56, \mathrm{SD}=6.62$ ). The mean number of missing days was $3.56(\mathrm{SD}=5.15$, range $0-15)$. The mean total number of interactions was 248 ( $\mathrm{SD}=92.59$, range 114$360)$. The mean daily number of interactions was 3.91 $(\mathrm{SD}=1.10$, range $0-16)$.

\section{Mood and Interpersonal Behaviour across the Menstrual Cycle}

Model 1 fitted the ECR data consistently much worse than the other models (Table 2). As model 3 had the best fit with the NA data, we found no evidence for menstrual cyclicity in NA. If there had been cyclicity in NA, then including the menstrual phases in model 4 should have provided a substantial improvement in model fit compared to model 3. We also found no evidence for cyclicity in PA, quarrelsomeness, and agreeableness. For all 3 variables, model 2 had the best fit. We checked whether the fit would improve with median, minimum, or maximum daily scores, rather than daily averages. Results (see https://osf.io/j7ngw/) provided no indications for altered conclusions.

When the analyses were repeated in the 3 participants (A to C) who reported the most severe PMS symptoms and the most interference in daily life on the PSST, and the most severe cyclical change in symptoms on the PAF, and the pattern was similar to that of all 9 participants (Table 2). In sum, we found no evidence for menstrual phase differences in mood and interpersonal behaviour. 
Table 2. DIC values for models fitted to the entire sample or to the participants with the highest PSST scores

\begin{tabular}{|c|c|c|c|c|c|c|c|c|}
\hline \multirow[b]{2}{*}{ Model } & \multicolumn{4}{|c|}{ Entire sample $(n=9)^{\mathrm{a}}$} & \multicolumn{4}{|c|}{ Highest PSST scores $(n=3)^{\mathrm{c}}$} \\
\hline & NA & PA & $\begin{array}{l}\text { quarrel- } \\
\text { someness }\end{array}$ & $\begin{array}{l}\text { agree- } \\
\text { ableness }\end{array}$ & NA & $\mathrm{PA}$ & $\begin{array}{l}\text { quarrel- } \\
\text { someness }\end{array}$ & $\begin{array}{l}\text { agree- } \\
\text { ableness }\end{array}$ \\
\hline 1 (number of days per person) & $-2,222$ & -759 & $-1,091$ & $-1,058$ & -727 & -363 & -436 & -432 \\
\hline 2 (number of social interactions) & $-2,311^{\mathrm{b}}$ & $-846^{\mathrm{b}}$ & $-1,932^{\mathrm{b}}$ & $-1,704^{\mathrm{b}}$ & $-771^{b}$ & $-429^{b}$ & $-738^{\mathrm{b}}$ & $-694^{\mathrm{b}}$ \\
\hline 3 (moving average) & $-2,336^{\mathrm{b}}$ & -855 & $-1,925$ & $-1,697$ & $-787^{\mathrm{b}}$ & -425 & -739 & -697 \\
\hline $\begin{array}{l}\text { 4A (group dummy variables for phases of } \\
\text { the menstrual cycle) }\end{array}$ & $-2,334$ & -850 & $-1,919$ & $-1,692$ & -790 & -427 & -734 & -700 \\
\hline $\begin{array}{l}\text { 4B (individual dummy variables for phases of } \\
\text { the menstrual cycle) }\end{array}$ & $-2,335$ & -857 & $-1,896$ & $-1,690$ & -790 & -423 & -726 & -700 \\
\hline
\end{tabular}

DIC, deviance information criterion; NA, negative affect; PA, positive affect; PSST, Premenstrual Symptom Screening Tool. ${ }^{a}$ DIC values can only be compared for models on the same data [17]. The DIC values of NA are lower than those of PA, and this is due to more variation in the NA values compared to the PA values and not necessarily to a better model fit. ${ }^{\mathrm{b}}$ The decrease from the previous model exceeds $10 .{ }^{\mathrm{c}}$ Participants A to C.

As the dependent variables were aggregated into daily means, it is possible that cyclicity of NA, PA, quarrelsomeness, and agreeableness was confounded by menstrual cyclicity in the occurrence of a specific social context. However, when we investigated whether this was the case, the additional analyses provided no indications for altered conclusions (also see https://osf.io/j7ngw/).

\section{User Experiences with TEMPEST}

Participants occasionally reported issues with the software not responding or responding slowly. Nonetheless, their mean SUS score was $84.17(\mathrm{SD}=7.60)$, indicating an overall positive experience.

\section{Discussion}

In 9 women with self-reported PMS we found no evidence for variation in mood (NA and PA) and interpersonal behaviour (quarrelsomeness and agreeableness) across the menstrual cycle. Thus, according to our prospective ECR data, the premenstrual phase of our participants did not appear to be characterized by 3 core symptoms of PMS, i.e., depressed mood, anxiety/tension, and irritability. However, on the PSST, participants reported these symptoms retrospectively, thereby indicating that they had PMS. This inconsistency suggests that prospective methods may be needed for diagnosing PMS in individual women, similar to what is currently required for PMDD [1].

Discrepant retrospective and prospective mood assessments have been reported previously. Ainscough [19] used the Moos Menstrual Distress Questionnaire to as- sess NA daily for 8 weeks in 51 women. Most participants retrospectively reported having experienced premenstrual mood symptoms; however the Moos Menstrual Distress Questionnaire data provided no indication of menstrual cyclicity in NA. Our study adds that retrospectively reported PMS may also not be reflected in prospectively measured PA or in prospective measures of interpersonal behaviour rather than mood.

Our results suggests the PSST, a retrospective measure, may be invalid for diagnosing PMS. Other retrospective measures have also been found to result in symptom overestimation [5]. Nonetheless, it has also been reported that the PSST yields prevalence rates of PMDD and PMS that are comparable to rates reported in prospective studies [11], and that retrospective and prospective assessment of premenstrual symptoms are positively correlated [20]. Thus, also given our small sample size, more research on the validity of the PSST is warranted.

An additional aim of our study was to evaluate the TEMPEST software for data collection [10]. Offering the ECR questionnaires online had several advantages. First, while previous paper-based studies provided participants with 10 questionnaires per day, in the present study participants could complete as many questionnaires as they wished (the daily maximum was 16). Second, there was no need to return the completed questionnaires by post, which reduced the study burden and missing data. Third, we could monitor whether participants completed the ECR questionnaires regularly. This was communicated beforehand to prevent backfilling questionnaires, for example when participants forgot to carry or charge their phone, which occurred infrequently. Importantly, participants evaluated their overall experience with TEMPEST as positive. 
In our study, the premenstrual phase was defined as the 5 days preceding menstruation. However, the number of days during which symptoms are reported can vary between women, as well as within women between menstrual cycles [21]. We also fitted models in which the length of the premenstrual and postmenstrual phases was 7 days, but again no cyclicity was found (model outcomes are available at https://osf.io/j7ngw/). Nonetheless, to gain more insight into cycle phases, daily measures of hormone levels or body temperature could have been included.

The small sample size may be considered another limitation. However, we were interested in menstrual cyclicity in mood and interpersonal behaviour in individual women. Clinically, these are more relevant than group effects. Nonetheless, replication in larger samples is recommended.

In conclusion, women who report having PMS on the PSST, a retrospective measure, may prospectively show no menstrual cyclicity in mood and interpersonal behaviour. This conclusion is preliminary in light of this study's limitations but supports the idea that a PMS diagnosis cannot be made using retrospective measures alone and, like for PMDD, should include prospective measures.

\section{Acknowledgment}

This study was funded by the Innovation Research Incentives Scheme Veni of the Netherlands Organization for Scientific Research (NWO) via a grant awarded to Dr. aan het Rot (No. 451-09013).

\section{Funding Sources}

The NWO had no role in the study design, data collection and analysis, the decision to publish, or in the preparation of this paper.

\section{References}

1 American Psychiatric Association: Diagnostic and Statistical Manual of Mental Disorders, ed 5. Washington, American Psychiatric Association, 2013.

2 Pincus SM, Schmidt PJ, Palladino-Negro P, Rubinow DR: Differentiation of women with premenstrual dysphoric disorder, recurrent brief depression, and healthy controls by daily mood rating dynamics. J Psychiatr Res 2008;42:337-347.

3 Gehlert S, Hartlage S: A design for studying the DSM-IV research criteria of premenstrual dysphoric disorder. J Psychosom Obstet Gynecol 1997; 18:36-44.

4 Heinemann LA, Minh TD, Heinemann K, Lindemann M, Filonenko A: Intercountry assessment of the impact of severe premenstrual disorders on work and daily activities. Health Care Women Int 2012;33:109-124.

5 Haywood A, Slade P, King H: Assessing the assessment measures for menstrual cycle symptoms: a guide for researchers and clinicians. J Psychosom Res 2002;52:223-237.

6 Shiffman S, Stone AA, Hufford MR: Ecological momentary assessment. Annu Rev Clin Psychol 2008;4:1-32.

7 Steinberg EM, Cardoso GMP, Martinez PE, Rubinow DR, Schmidt PJ: Rapid response to fluoxetine in women with premenstrual dysphoric disorder. Depress Anxiety 2012;29: 531-540.
8 Csikszentmihalyi M, Larson R: Validity and reliability of the experience sampling method. J Nerv Ment Dis 1987;175:526-536.

9 Moskowitz DS, Sadikaj G: Event-contingent recording; in Mehl MR, Conner TS (eds): Handbook of Research Methods for Studying Daily Life. New York, Guilford, 2013, pp 160175.

10 Batalas N, Markopoulos P: Introducing Tempest, a modular platform for in situ data collection. 7th Nord Conf Hum-Comput Interact: Making Sense Des. Copenhagen, 2012, pp 781-782.

11 Steiner M, Macdougall M, Brown E: The Premenstrual Symptoms Screening Tool (PSST) for clinicians. Arch Womens Ment Health 2003;6:203-209.

12 Allen SS, McBride CM, Pirie PL: The shortened premenstrual assessment form. J Reprod Med 1991;36:769-772.

13 Rush AJ, Trivedi MH, Ibrahim HM, Carmody TJ, Arnow B, Klein DN, Markowitz JC, Ninan PT, Kornstein S, Manber R, Thase ME, Kocsis JH, Keller MB: The 16-item Quick Inventory of Depressive Symptomatology (QIDS), Clinician Rating (QIDS-C), and Self-Report (QIDS-SR): a psychometric evaluation in patients with chronic major depression. Biol Psychiatry 2003;54:573-583.
14 Brooke J: SUS: a quick and dirty usability scale. Usability Eval Ind 1996;189:4-7.

15 aan het Rot M, Hogenelst K, Moskowitz DS Comparability of the Social Behavior Inventory in English and Dutch. J Pers Assess 2013; 2013:5.

16 Diener E, Emmons RA: The independence of positive and negative affect. J Pers Soc Psychol 1984;47:1105-1117.

17 Spiegelhalter DJ, Best NG, Carlin BP, Van Der Linde A: Bayesian measures of model complexity and fit. J R Statist Soc Series B Statist Methodol 2002;64:583-639.

18 Barendse MT, Albers CJ, Oort FJ, Timmerman ME: Measurement bias detection through Bayesian factor analysis. Front Psychol 2014;5:1087.

19 Ainscough CE: Premenstrual emotional changes a prospective study of symptomatology in normal women. J Psychosom Res 1990; 34:35-45.

20 Steiner M, Streiner DL: Validation of a revised visual analog scale for premenstrual mood symptoms: results from prospective and retrospective trials. Can J Psychiatry 2005;50: 327-332.

21 Pearlstein T, Yonkers KA, Fayyad R, Gillespie JA: Pretreatment pattern of symptom expression in premenstrual dysphoric disorder. J Affect Disord 2005;85:275-282. 